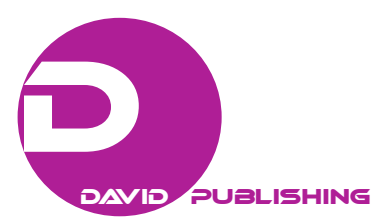

\title{
Going Away From the "Protocol Culture”: Innovation, Complexity and the Need for a Culture of Variety
}

\author{
Mario Calabrese, Cristina Simone \\ Sapienza University of Rome, Rome, Italy \\ Pierpaolo Magliocca \\ University of Foggia, Foggia, Italy
}

\begin{abstract}
The paper starts with the largely accepted definition of culture as set of experiences or life practices and values. After criticizing the "culture of the protocol", the paper develops a concept antithetical to it: the culture of variety, seen as the necessary richness of the values endowment of the organizations that want to innovate and survive in complex contexts. The paper is framed in the Viable System Approach (VSA). According to the VSA, information variety is articulated in three dimensions: informative units, interpretative schemes, and values. The last one is just the cultural dimension and its nature (rich or poor in variety) deeply influences the cognitive capability of a system (individual or organization) in promoting, accepting, or refusing the change. The VSA proposal linking information variety to values is new and it could lead to original insight in understanding the role of cultural values in promoting (or impeding) innovation in complex environment.
\end{abstract}

Keywords: culture of protocol, culture of variety, innovation, complexity, Viable Systems Approach (VSA)

\section{Introduction}

The term "culture" originally referred to the cultivation of crops and rearing of animals. Its meaning was then extended metaphorically to the "cultivation" of the mind and the human spirit (Williams, 1983). According to the cultural metaphor, the society would cultivate the mind and spirit of human beings through the family, society, schools, and religious practices, just as farmers and ranchers are taking care of their crops and their animals through planting and pruning on the one hand, and the nutrition and grazing on the other (Hatch, 1997). Culture is one of the most important pillars of the social order of a group: the cultures and subcultures connect (and divide) people both at an emotional and a rational level (Wilson, 2004). All definitions explicitly associate with the concept of culture to the group and all refer to something that members of the group have in common or share: meanings, assumptions, cognitive frame, norms, values, and nowledge. The widely accepted definitions (Jacques, 1952; Pettigrew, 1979; Louis, 1983; Siehl \& Martin, 1984; Schein, 1985; Trice \& Beyer, 1993, pp. 419-420) focus on the "sharing” processes to describe the culture as social phenomenon. But what do we share? What do we hand down? Which set of values, heritage, and mental habits?

Mario Calabrese, adjunct professor, Department of Management, Sapienza University of Rome, Rome, Italy.

Cristina Simone, associate professor, Department of Management, Sapienza University of Rome, Rome, Italy.

Pierpaolo Magliocca, researcher, Department of Economics, University of Foggia, Foggia, Italy.

Correspondence concerning this article should be addressed to Cristina Simone, Department of Management, Sapienza University of Rome, via del Castro Laurenziano, 9-00161 Rome, Italy. 
The impression is that human beings are like that old Eskimo, to which an ethnographer wondered why his tribe kept devoutly certain rites the wise old man admits he does not understand the meaning: "We preserve our ancient customs - he answered - to keep intact the universe”. The social universe is the universe for that Eskimo: human beings perceive the existence of relative harmony, a global mechanism that works or deteriorates, but they do not know maneuver gears; in doubt, they preserve all that they can, with the risk sometimes, to prevent precisely the proper functioning. Individuals and organizations are not yet cognitively and culturally adapted to face the contemporary social situation: this is the most important fact of which individual and organizations must realize in order to move in complex environment characterized by high interdependence and nonlinearity. The paper brings back much of that inability to a specific model of culture, the "culture of protocol", and it indicates the antithetical "culture of the variety" (sections 2 and 3) as the set of values that leads to innovation and to sustainable fit between organizations and complex environments (section 4); theoretical and managerial implications related to the "culture of variety" are then discussed in conclusions.

\section{Going Away From the Culture of the Protocol: The Culture of Variety}

At all levels, the educational system, from primary school just to the business schools, induces the younger generations the belief of being part of a species (human) powerful and, overall, suitable to aspire to infallibility leaded in different degrees of social system by decision makers competent and reliable (even if fallible). The generation of people educated according to these principles is named the "protocol generation". From the medical sciences to the sciences of management, thanks to the public administration, professionals, and any other social actors, any behavior is leaded by a sort of formulary, by manuals of "right" rules to follow in each situation (Birkinshaw \& Piramal, 2005). The "protocol culture" is rising and it is permeating different social areas and management, in particular, it is increasingly considered as a hard science, with methods, techniques, and tools that are more and more perfectible. However, the severe respect of this set of values passes through a crisis when you find yourself having to horizontal leveraging the heterogeneous capabilities of individuals, capabilities that are crucial in complex environment. The need to leverage the lateral thinking and the need to tap into heterogeneous cognitive slack geographically and industrially dispersed do not agree with the culture of protocol. The challenge of complexity asks for an antithetical culture-the culture of variety_based on a necessary heterogeneity granted by the following coherent five categorical values.

1. Diversity is source of value and creativity. Primary diversity (age, ethnicity, gender, physical abilities, cognitive capabilities, sexual, and emotional orientation) and diversity of the second level (education, work experience, income, marital status, religious, geographical origin, family status, and personal style) (Bradford, 2007) are at the basis of the culture of variety. The consciousness of the multiplicity of human experiences and how this diversity is a positive factor for the survival of a group (Denison, 1990) and it is source of value, creativity, and competitive advantage (D. A. Thomas, 2004; K. M. Thomas, 2004).

2. People are neghentropic resources. For troubleshooting high cognitive and computational complexity, such as those of $R \& D$ and more generally of innovative processes, organizations increasingly need to get to the huge variety of human capabilities. The huge variety of human capabilities is the pivot to address the needs of knowledge sharing, brokering, exploring, and recombining typical of the complex environments. People can no longer be seen as elements of unpredictability to be normalized, but they should be viewed, taking as a 
metaphor dissipative structures of the Nobel Prize for Physics Ilya Progogine, as true neghentropic resources, neghentropic resources are able to generate connections among ideas, organizations, countries, cultures, and scientific fields, and able to widen the range of strategic alternatives (De Toni, Comello, \& Ioan, 2011). It is this vision of people as neghentropic resources the value that urges the adoption of a distributed logic in designing organizational structures.

3. Self-organizing is an organizational need. How to co-exist the quality of the technique (i.e., its depth and its mastery) with the emergence of the need for knowledge sharing, seeking, and re-combining and for cooperation among people to an ever-increasing scale in complex environments? To effectively address this problem, it is firstly asked to profoundly rethink the mental models that organizations have inherited from ancient and more recent history, in particular, the principle of hierarchical authority and the principle of extreme labor division. The metaphor of the pyramid building belongs to the past; according to the the culture of variety the new metaphor is that of a multi-polar fluid network. A mainly emergent structure, self-organized and designed on a distributed logic, allows, firstly, tapping into cognitive slack, i.e. directories, repositories of knowledge, experience, and creativity otherwise it will be difficult to access on the basis of a top-down design conceived; and, secondly, amplifying a much larger scale the potential of the individual set of capabilities.

4. Error is an opportunity to learn. Consistency and persistence are positively assessed by the culture of the protocol. On the contrary, the culture of variety conceives the work as a human activity to invent world based on freedom to experiment. Double loop learning is linked to the presence of an organizational context in which the exploration of new ideas, experimenting with alternative ways, and admission of error is not immediately sanctioned (Popper, 1962; De Bono, 1970; Weick, 1979; Senge, 1992). To ensure this, it is necessary to promote a vision of the error as a positive value and not as a deviation from perfection: the error is not the negative deviation from an absolute truth, but rather a positive tool in the pragmatic and contingent human learning process (Andreoli \& Provasi, 2011).

5. The boundary is something to break. According to the culture of protocol, the boundary means efficiency and maximum specialization in problems solving frame. But this gives rise to the so called "sylos effect": isolation of individuals and departments in separate, poorly communicating units, where you gather information that would be valuable to other areas of the system organization. But solving a complex problem needs something more than the specialist technical knowledge: the boundaries among research fields, disciplines, industries, technological trajectory, and business units must be deliberately ambiguous to foster knowledge hybridization and fertilization. Culture of variety means thinking in a more complex way than the culture of protocol does: it leads to thinking in multiple dimensions simultaneously (vertical and lateral), in an inclusive manner and not to trade-offs.

Considering five fundamental dimensions, Figure 1 represents the culture of protocol and the culture of variety as two polar sets of coherent categorical values.

\section{Innovating in Complex Environment: The Supporting Role of Culture of Variety}

It is obvious that from the pervasive impact of distant events, both natural and man made, individuals and organizations move in a complex and interdependent world. Even when a given event is local, it could have global effects: from a complex system perspective, interactions between and among the different system's units and the system's behaviour_as a whole—are critical (Surie \& Hazy, 2006). Innovation has been considered, 
for a long time, as the best solution to solve any crisis arising at both firms' and environmental level. It becomes particularly true with reference to complex environments (Ashby, 1956). Following the explained theoretical considerations, researchers are claimed to answer some relevant questions: Why do firms innovate? How do they innovate and how does the culture of variety allow innovation in complex environments?

\begin{tabular}{|c|c|c|}
\hline $\begin{array}{c}\text { Costly } \\
\text { counterproductive } \\
\text { ceavly inhibitory }\end{array}$ & Vision of the diversity & $\begin{array}{c}\text { Source of value } \\
\text { Source of creativity } \\
\text { Source of competitive advantage }\end{array}$ \\
\hline $\begin{array}{l}\text { Elements of unpredictability } \\
\text { to be normalized }\end{array}$ & Vision of people & Neghentropic resources \\
\hline Need for heriarchy & Vision of the coordination problem & Need for self-organizing \\
\hline Unwelcome deviance & Vision of the error & Opportunity to learn \\
\hline $\begin{array}{l}\text { Premise for economies } \\
\text { of specialization }\end{array}$ & Concept of boundary & Something to break \\
\hline
\end{tabular}

Figure 1. Culture of protocol and culture of variety: The five fundamental categorical values.

An innovation is a new idea and it may be a new combination of old ideas, or a scheme that challenges the current order, or a unique approach which is perceived as new by the involved individuals (Zaltman, Duncan, \& Holbek, 1973; Rogers, 2003; Van de Ven, 1986). As long as the idea is perceived as new to the involved people, it is an "innovation", even though it may appear to others to be an "imitation" of something that exists elsewhere (Van de Ven, 1986). Innovation in organizations is at the same time technical innovation—new technologies, products, and services-and administrative innovations-new procedures, policies, and organizational forms (Van de Ven, 1986; Damanpour, 1991; Surie \& Hazy, 2006), and may be incremental or radical (Kuhn, 1970; Henderson \& Clark, 1990). In any case, innovation improves firms' performance and their competitive advantage, as it is supported by Tidd (2001).

Table 1 shows the way each type of innovation fosters the emergence of firms' competitive advantage.

Table 1

Innovation and Competitive Advantage

\begin{tabular}{|l|l|}
\hline Type of innovation & Competitive advantage \\
\hline Disruptive & Re-writing the rules of the competitive games, creating a new “value proposition” \\
\hline Radical & Offering a highly novel or unique product or service, premium pricing \\
\hline Complex & Difficulty of learning about the technology keeps entry barriers high \\
\hline Continuous incremental innovation & Continuous movement of the cost/performance frontier \\
\hline
\end{tabular}


Developing and promoting innovation needs:

- a diversity of experience and expertise to allow pooling of relevant knowledge coming from various sources (Cohen \& Levinthal, 1990; Ancona \& Caldwell, 1992; Dougherty \& Hardy, 1996);

- repeated practice (Pisano, 2000) or cognitive search (Gavetti \& Levinthal, 2000);

- ability to isolate the group from everywhere pressures, and provide resources to permit sustained and focused activity on specific projects (Leonard-Barton, 1995; Shane, Venkataraman, \& MacMillan, 1995; Dougherty \& Hardy, 1996);

- ongoing challenges on which organizational survival depends (Dougherty \& Hardy, 1996);

- testing innovations such as to determine whether it is appropriate to continue to pursue specific trajectories of innovation (Clark \& Fujimoto, 1991; March, 1991).

Scholars have examined innovation in different contexts: technology adoption (Rogers, 2003; Van de Ven, 1986; Van de Ven, Angle, \& Poole, 1989), culture (Shane et al., 1995), creativity (Amabile, Conti, Coon, Lazenby, \& Herron, 1996), learning, capability building, exploration, and exploitation (March, 1991; Winter \& Szulanski, 2001), performance (Lawless \& Anderson, 1996), sources of innovation (Wade, 1996; Von Hippel, 1988, pp. 111-120), and characteristics of innovation adopters (Greve, Strang, \& Tuma, 1995). However, few studies link innovation with culture of variety and complex environment explaining how the culture of the variety allows innovation in complex environments.

Several authors (Burns \& Stalker, 1961; Lawrence \& Lorsch, 1967; Perrow, 1967; 1970; Gerloff, 1973; Hofstede, 1978) — which belong to the organizational theories ground-examined the trade off between organizational models and the "quality" of the environment. Following the mentioned authors, according to the mentioned authors, not all the types of culture are the best suitable ways to manage complex environments. Moving from this organizational perspective, the following of this section argues that culture (protocol vs. varieties) has to fit with environmental characteristics (simple vs. complex).

As it is showed in Figure 2, the environment (simple or complex) and the cultural type (culture of protocol or culture of variety) may be crossed, suggesting the following considerations:

- culture of protocol/simple environment (quadrant 1) - since the environmental stability, the culture of protocol allows efficiency, the emergence of scale economies, the establishment of leadership in single loop learning, and knowledge exploitation. In such situation, the ideal fit between culture and environment is granted;

- culture of variety/simple environment (quadrant 2) -when culture variety crosses with simple environment the risk of failure in knowledge exploitation may arise, mainly because of the redundancy in cultural variety, the last one also responsible for a high degree of inefficiency. It is like to say that culture offers more than the environment requires;

- culture of variety/complex environment (quadrant 3) - since the environmental complexity, the culture of variety is necessary to manage the rapid environmental changes. When culture of variety fits with complex environment, the best solution is established to foster complex learning processes and leadership in knowledge exploration. Since innovation embeds itself in learning processes, the culture of variety supports firms' innovative activities enabling them to proactively compete to reach the business' goals. According to this perspective, culture (from culture of protocol to culture of variety), affects innovation in a very different way with reference to environmental characteristics;

- culture of protocol/complex environment (quadrant 4) - since the environmental complexity, the culture of protocol does not answer to environmental changes. As noted above, the culture of protocol allows only single 
loop learning process limiting firms' capacity to innovate. It is like to say that culture offers less than the environment requires.

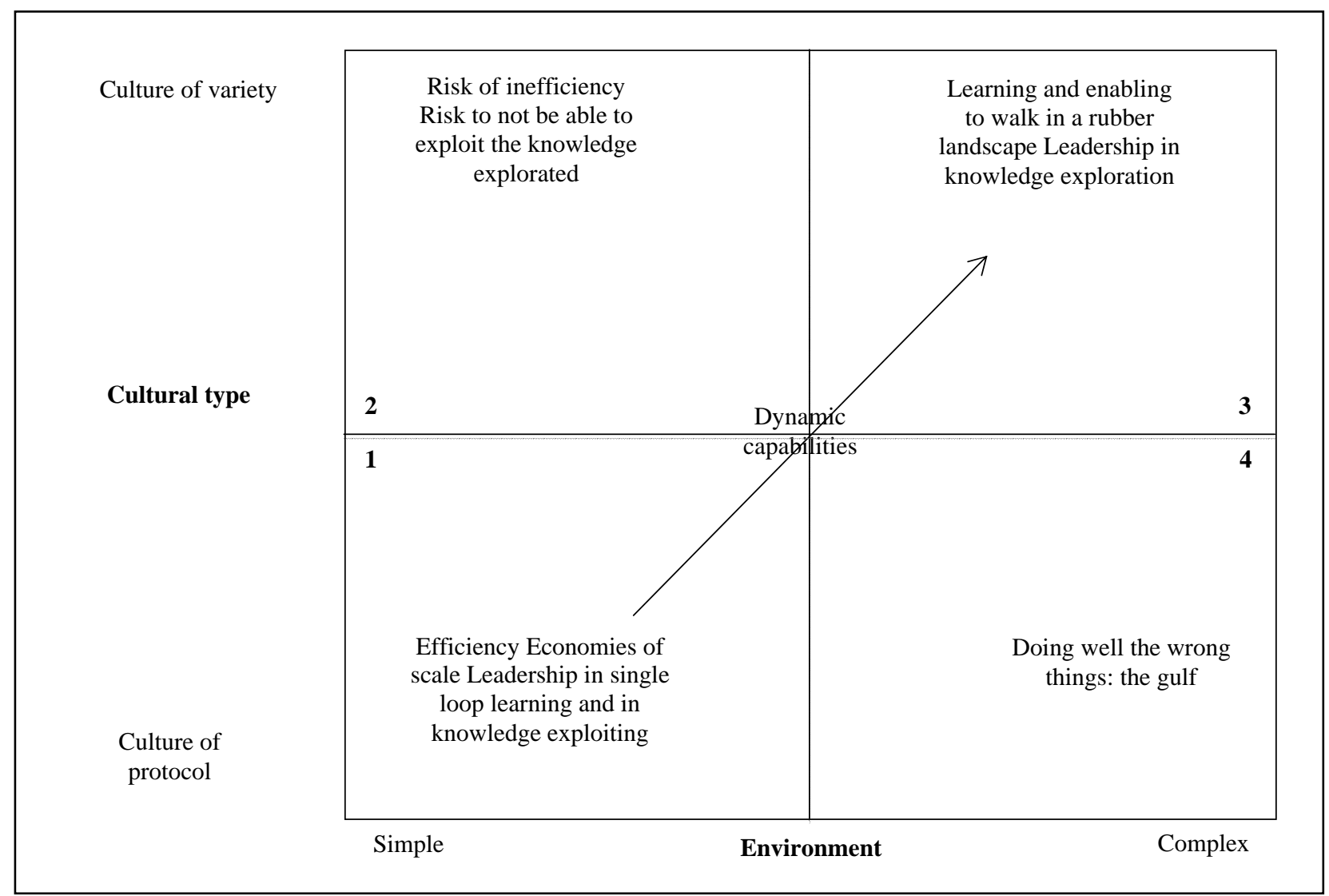

Figure 2. "Environment-Culture” Matrix.

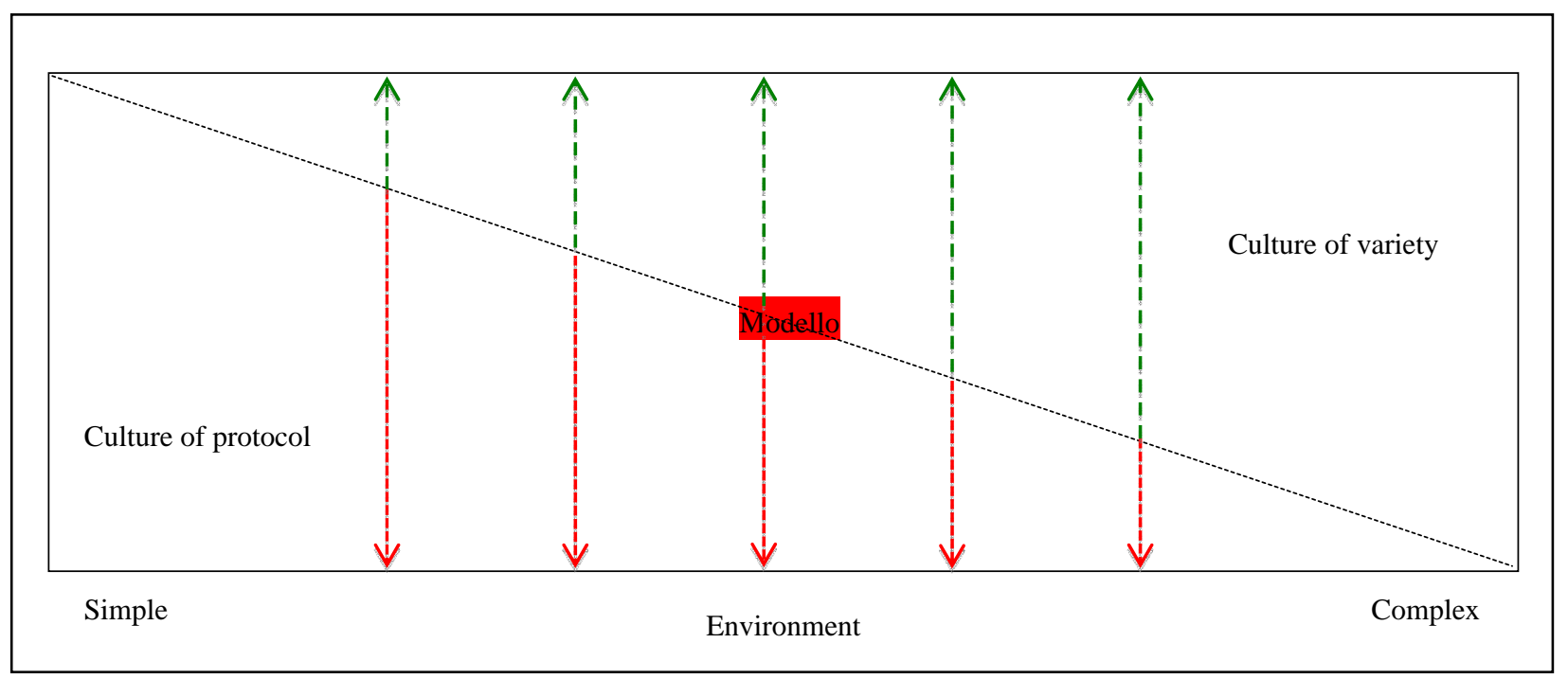

Figure 3. From simple to complex environment: A cultural insight.

The "Environment-Culture" Matrix may be examined also by a dynamic perspective: moving from simple to complex environment, firms are required to renew their competences so as to achieve congruence with the 
changing business environment. It means that firms have to develop dynamic capabilities (Teece, Pisano, \& Shuen, 1997) to rapidly innovate and to gain competitive advantage.

Depending on the above, the culture of protocol fits for a simple environment, which characterizes for stability, predictability, linear dynamics, relations, well-known technological trajectories, and low interdependences among socio-economic phenomena. On the contrary, the culture of variety is better performed in complex environments, the last one is characterized by instability, unpredictability, non linear dynamics, and relations, Schumpeterian shocks, and high interdependences among socio-economic phenomena. When the environmental complexity increases, the need for culture of protocol reduces and needs for culture of variety, respectively, grow (see Figure 3).

\section{From the Categorical Values to the Information Variety: The Viable System Approach (VSA)}

According to the VSA, the set of coherent categorical values (protocol vs. variety) is one of the three fundamental dimensions framing the information variety of a decision maker (individual, firm, policy maker, etc.). The VSA, deriving from interdisciplinary researches, aims to study the nature of the organizations integrated into context of reference (Golinelli, 2010). Thanks to this new perspective of investigation, it is possible to see, in the organizations, two distinct areas: the area of strategic decisions chaired by the governing body and the other devoted to the routine decisions as well as to the performance of operational activities, explained as operational structure. In that approach, the structure, also understood as genotypic dimension, coincides with several semantics qualifications hardly used. It is relevant to think about the concept of the human body or about the concept of the nation; as it is easy to guess, the concept implies the presence of components connected to each other. The dimension of the process (phenotypic size), however, is studied through the use of the concept of the system. As for the system the physical boundary has no reason to exist, the function is compressed in a particular role and, above all, from the connections you switch to the concept of relationships. The latter, being activated, produce interactions among the components that allow the development of the system. The need to better understand the dynamics of competitive and collaborative relationships among organizations in general, and those linked to business in particular, leads to the definition of two fundamental conceptualizations: one about consonance and the other about resonance. Where consonance qualifies the greatest or the lowest capacity that interacting systems have to optimize the resources available in the course of their interactions, resonance is the orientation towards virtuous or vicious yields respectively increasing or decreasing over time. Recent developments made it possible to identify the size of useful representation to measure the levels of consonance and resonance. The basic idea consists in having established a substantial equivalence (isomorphism) between a viable system and a variety of information supplied, where the information variety is divided into three forming dimensions: categorical value, interpretation schemes, and information units (Barile, 2009):

$$
\begin{gathered}
\operatorname{Var}_{\text {inf }}(k)=\left(U_{\text {inf }}(k), S_{\text {int }}(k), C_{\text {val }}(k)\right) \text { with } \\
\operatorname{Var}_{\text {inf }}(k)=\text { informatin variety (or information heritage) of viable system } k \\
U_{\text {int }}(k)=\text { information units belonging to the information variety of viable system } k \\
S_{\text {int }}(k)=\text { interpretation schemes (synthesis) belonging to the information variety of viable system } k \\
C_{\text {val }}(k)=\text { categorical value belonging to the information variety of viable system } k
\end{gathered}
$$

With reference to the basis of the importance of supra-systems in the context and to the basis of the 
allocations of informative variety of the individual vital systems involved, with this latest conceptualization, you can look over the possible prospects of recovery of consonance and, therefore, on the identification of shared and accepted solutions.

Focusing on the search for solutions, a fundamental distinction between decisions belonging to two basic categories takes form of the one about problem solving and the other about decision making. The first choice is attributable to recurrent problems, already practiced, and for which methods for methodical tested solutions are proved. Basically, the problem solving refers to the concept of routine expressed by Nelson and Winter (1982). The routines play the same role in the enterprise that genes play in biological organisms: they are an intrinsic characteristic of the organization and determine its possible development. This is obviously awareness that is proposed through processes that become automatic responses to certain stimuli. The routines are nothing but knowledge that is proceduralized. The decisions belonging, instead, to the category of the decision making are attributable to that problems are too narrow, in which the application of any methodology, regardless of the technical difficulty and the burden of the calculation, becomes difficult, if not impossible, for lack of factual assumptions, that is conditions and constraints of the problem, and behavioral characteristics of the decision maker. It is important to understand and explain the consequences that cognitive schemes and culture have on managerial effectiveness. A new interpretation based on the belief that the decision-making constitutes the heart of the management and that the vocabulary of management theory should be derived from logic and psychology of human choice, is provided by recent studies (Tversky \& Kahneman, 1981). The hinges of the systemic vital management are the following basic tenets: 1) in the process of knowledge you have three modes of inference: abduction, induction, and deduction; 2) in the process of understanding the three types of inference are followed in constant and obliged order, coming to compose a kind of "curve of knowledge"; in abduction it has its first recruitment or premise, in induction it has its second moment of analysis or explicative; in deduction it has its third phase of assessment and thus of conclusion of the process; 3) the decision makers are represented through the variety of information, that is, every manager has his own endowment of knowledge resulting from the mix of value-categories that arise when attention is strongly attracted on complex circumstances so that thought cannot dominate them, of interpretive schemes that represent the tendency of a person to an action resulting from previous experience or from earlier efforts or acts of will, of from information units; 4) the decision makers are faced with the following different types of contexts: complex, complicated, and simple. Finally, it is clear there is a correspondence among the decision-making contexts, the various human inferences, and the mix of factors (value categories, interpretative schemes, and information units) characterizing a disclosure variety. But above all, at this point, it can be observed that: the interpretation of reality is possible through the establishment of a code resulting from the mix of categories, patterns, and information units of the decision maker. This code takes the form of an abstraction, so individuals and organizations decide to consider certain things considering them irrelevant and then select part of the content of message with free choice. These signals do not constitute relevant background noise, which limits the precision of the message (Hofstadter, 1979). As the code to decipher, the reality is not absolute, noise, and information are deeply related; what looks like noise to a certain level or in a certain place is information in another time or in another place (Taylor, 2001). It follows that intelligence is precisely the act of selecting relevant information in order to destroy, with competence and intention, all the rest (Kurzweil, 1999). 


\section{Conclusion}

The protocol culture is winning in environment characterized by high stability, predictability, and certainty, where the concepts of "standard", "repeatable and repetitive”, and "efficiency" are considered as a categorical imperative. On the contrary, the protocol culture is inefficacy in environment characterized by the emergence of complexity where innovation capability is vital. Culture of variety tips the search for economies of flexibility, creativity, and integration of knowledge rather than the conquest of economies of scale. The principle of requisite variety is not an abstract concept. Rather it is a very concrete managerial principle which is fundamental in the VSA: if an organization is not capable to change by adapting itself in response to external changes, it will not be able to survive. Here is a call for manager and researchers: to direct the development of business models. A shift to a more flexible, open, and responsible view of organizations, less focused on the "certainty" of the structure and technology, and open to the unpredictable outcomes of the human side of the system's dynamics which is essentially emergent in nature. As well as organizations of the past have been marked by the culture of protocol, the organizations of the future will need to be based on the culture of variety. What will be the new balance between the values of protocol and the values of variety? In which way and to what extent the command and control will be permeated by self-organization? Will the self-organizing networks crumble the pyramids? Some and important elements of the culture of protocol will not be eliminated, the principles of top-down and of work standardization will not disappear. But the "variety based" organizations will be organizational systems in which the protocol organizational mechanisms will be subjected to major stresses, due to the strong push towards multipolarity, the self-organization, the search for a local adaptation, though not excellent, satisfactory. In the most extreme versions, it will be organizational forms which tend to be cash equivalents: agents will have relevant degrees of freedom in the choice of their connection, and self-allocation of efforts towards the creation of a common value. The top-down logic, the hierarchy principle, and the hyper detemination obsession will be integrated, diluted with other principles, which will have to find a compromise. The logics, maybe sometimes collide, but over time will have to learn to share with them the realm of human organization.

\section{References}

Amabile, T. M., Conti, R., Coon, H., Lazenby, J., \& Herron, M. (1996). Assessing the work environment for creativity. Academy of Management Journal, 39(5), 1154-1184.

Ancona, D. G., \& Caldwell, D. F. (1992). Bridging the boundary: External activity and performance in organizational teams. Administrative Science Quarterly, 37(4), 634-665.

Andreoli, V., \& Provasi, G. (2011). Elogio dell'errore. Milano: Bur Rizzoli.

Ashby, W. R. (1956). An introduction to cybernetics. London: Chapman \& Hall.

Barile, S. (2009). Management sistemico vitale. Torino: Giappichelli.

Birkinshaw, J., \& Piramal, G. (2005). Sumatra Ghoshal on management: A force for good. Harlow, Upper Saddle River (NJ): Prentice Hall.

Bradford, S. (2007). Fourteen dimensions of diversity: Understanding and appreciating differences in the work place. The Pfeiffer Book of Successful Team-Building Tools: Best of the Annuals, 225.

Burns, T., \& Stalker, G. M. (1961). The management of innovation. London, England: Tavistock Institute.

Clark, K. B., \& Fujimoto, T. (1991). Product development performance: Strategy, organization, and management in the world auto industry. Cambridge: Harvard Business Press.

Cohen, W. M., \& Levinthal, D. A. (1990). Absorptive capacity: A new perspective on learning and innovation. Administrative Science Quarterly, 35(1), 128-152.

Damanpour, F. (1991). Organizational innovation: A meta-analysis of effects of determinants and moderators. Academy of 
Management Journal, 34(3), 555-590.

De Bono, E. (1970). Lateral thinking. A textbook of creativity. Mica Management Resources, UK.

De Toni, A. F., Comello, L., \& Ioan, L. (2011). Auto-organizzazioni: Il mistero dell'emergenza nei sistemi fisici, biologici e sociali. Venice: Marsilio Editori.

Denison, D. R. (1990). Corporate culture and organizational effectiveness. Hoboken (NJ): John Wiley \& Sons.

Dougherty, D., \& Hardy, C. (1996). Sustained product innovation in large, mature organizations: Overcoming innovation-to-organization problems. Academy of Management Journal, 39(5), 1120-1153.

Gavetti, G., \& Levinthal, D. (2000). Looking forward and looking backward: Cognitive and experiential search. Administrative Science Quarterly, 45(1), 113-137.

Gerloff, E. A. (1973). Performance control in government R\&D projects: The measurable effects of performing required management and engineering techniques. Engineering Management, IEEE Transactions on Engineering Management, 1, 6-14.

Golinelli, G. M. (2010). Viable systems approach (VSA): Governing business dynamics. Padova: Cedam.

Greve, H. R., Strang, D., \& Tuma, N. B. (1995). Specification and estimation of heterogeneous diffusion models. Sociological Methodology, 25, 377-420.

Hatch, M. J. (1997). Teoria dell'organizzazione. Bologna: Il Mulino.

Henderson, R. M., \& Clark, K. B. (1990). Architectural innovation: The reconfiguration of existing product technologies and the failure of established firms. Administrative Science Quarterly, 35(1), 9-30.

Hofstadter, D. R. (1979). Godel escher bach. New York: New Society.

Hofstede, G. (1978). The poverty of management control philosophy. Academy of Management Review, 3(3), 450-461.

Jacques, E. (1952). The changing culture of factory. New York: Dryden Press.

Kuhn, T. S. (1970). The structure of scientific revolutions (2nd ed.). Chicago: University of Chicago Press.

Kurzweil, R. (1999). The age of spiritual machines: When computers exceed human intelligence. London: Penguin.

Lawless, M. W., \& Anderson, P. C. (1996). Generational technological change: Effects of innovation and local rivalry on performance. Academy of Management Journal, 39(5), 1185-1217.

Lawrence, P. R., \& Lorsch, J. W. (1967). Differentiation and integration in complex organizations. Administrative Science Quarterly, 12(1), 1-47.

Leonard-Barton, D. (1995). Wellsprings of knowledge: Building and sustaining the sources of innovation. University of Illinois at Urbana-Champaign's Academy for Entrepreneurial Leadership Historical Research Reference in Entrepreneurship.

Louis, M. R. (1983). Organizations as culture-bearing milieux. Organizational Symbolism, 39, 54.

March, J. G. (1991). Exploration and exploitation in organizational learning. Organization Science, 2(1), 71-87.

Nelson, R., \& Winter, S. (1982). An evolutionary theory of economic change. Cambridge: Harvard Univ. Press.

Perrow, C. (1967). A framework for the comparative analysis of organizations. American Sociological Review, 32(2), 194-208.

Perrow, C. (1970). Organizational analysis: A sociological view. Wadsworth, CA: Belmont.

Pettigrew, A. M. (1979). On studying organizational cultures. Administrative Science Quarterly, 24(4), 570-581.

Pisano, G. P. (2000). In search of dynamic capabilities: The origins of R\&D competence in biopharmaceuticals (pp. 129-154). Oxford: Oxford University Press.

Popper, K. R. (1962). On the sources of knowledge and of ignorance. Conjectures and refutations: The growth of scientific knowledge. London: London Routledge and Kegan Paul.

Rogers, E. M. (2003). Diffusion of innovations (5th ed.). New York: Free Press.

Schein, E. H. (1985). Organizational culture and leadership. San Francisc: Jossey \& Bass.

Senge, P. M. (1992). La quinta disciplina. L'arte e la pratica dell'apprendimento. Milano: Sperling \& Kupfer.

Shane, S., Venkataraman, S., \& MacMillan, I. (1995). Cultural differences in innovation championing strategies. Journal of Management, 21(5), 931-952.

Siehl, C., \& Martin, J. (1984). The role of symbolic management: How can managers effectively transmit organizational culture. Leaders and Managers: International Perspectives on Managerial Behavior and Leadership, 7, 227-239.

Surie, G., \& Hazy, J. K. (2006). Generative leadership: Nurturing innovation in complex systems. Emergence Mahwah Lawrence Erlbaum, 8(4), 13.

Taylor, M. C. (2001). The moment of complexity: Emerging network culture. University of Chicago Press.

Teece, D. J., Pisano, G., \& Shuen, A. (1997). Dynamic capabilities and strategic management. Strategic Management Journal, 18(7), 509-533.

Thomas, D. A. (2004). Diversity as strategy. Harvard Business Review, 82(9), 98-98. 
Thomas, K. M. (2004). Diversity dynamics in the workplace. Belmont (CA): Wadsworth Publishing Company.

Tidd, J. (2001). Innovation management in context: Environment, organization and performance. International Journal of Management Reviews, 3(3), 169-183.

Trice, H. M., \& Beyer, J. M. (1993). The cultures of work organizations. Englewood Cliffs, NJ: Prentice Hall.

Tversky, A., \& Kahneman, D. (1981). The framing of decisions and the psychology of choice. Science, 211(4481), $453-458$.

Van de Ven, A. H. (1986). Central problems in the management of innovation. Management Science, 32(5), 590-607.

Van de Ven, A. H., Angle, H. L., \& Poole, M. S. (Eds.). (1989). Research on the management of innovation: The Minnesota studies (Vol. 1). Cambridge (MA): Ballinger Publishing Company.

Von Hippel, E. (1988). The sources of innovation. New York: Oxford University Press.

Wade, J. (1996). A community-level analysis of sources and rates of technological variation in the microprocessor market. Academy of Management Journal, 39(5), 1218-1244.

Weick, K. E. K. E. (1979). The social psychology of organizing (2nd ed.). New York: Addison Welsey. Williams, R. (1983). Keywords: A vocabulary of culture and society. Oxford: Oxford University Press. Wilson, F. M. (2004). Lavoro e organizzazioni. Bologna: Il Mulino.

Winter, S. G., \& Szulanski, G. (2001). Replication as strategy. Organization Science, 12(6), 730-743.

Zaltman, G., Duncan, R., \& Holbek, J. (1973). Innovations and organizations. New York: Wiley. 